\title{
Subang Jaya Residents' Awareness and Practice of Biomass Waste Management
}

\author{
Siti Mazwin Kamaruddin¹,Mohd Hafiz Sharif2, \\ Alamah Misni ${ }^{1}$, Puziah Ahmad ${ }^{1}$ \\ ${ }^{1}$ Faculty of Architecture, Planning and Surveying \\ Universiti Teknologi MARA, Malaysia \\ ${ }^{2}$ Majlis Perbandaran Subang Jaya, 47610 Subang Jaya Selangor Malaysia \\ sitim065@salam.uitm.edu.my
}

\begin{abstract}
Public awareness and active engagement in environmental programmes are associated with a better quality of life (Kamaruddin et.al. 2016; Mohit 2016). This exploratory study highlights the level of awareness and practice of residents in the bio mass initiative of a case study area. Self reported descriptive responses indicate that having awareness and knowledge regarding waste management does not necessarily result in actual sustainable waste practice. This paradox is consistent with other findings of similar studies (Kamaruddin et.al. 2016). Practical steps are identified to encourage residents and help sustain the bio mass initiative programme implemented by a local authority in Selangor, Malaysia.
\end{abstract}

Keywords: Biomass Program, Community Involvement

eISSN 2398-4279 @ 2018. The Authors. Published for AMER ABRA cE-Bs by e-International Publishing House, Ltd., UK. This is an open access article under the CC BY-NC-ND license (http://creativecommons.org/licenses/bync-nd/4.0/). Peer-review under responsibility of AMER (Association of Malaysian Environment-Behaviour Researchers), ABRA (Association of Behavioural Researchers on Asians) and CE-Bs (Centre for EnvironmentBehaviour Studies), Faculty of Architecture, Planning \& Surveying, Universiti Teknologi MARA, Malaysia.

DOI: https://doi.org/10.21834/ajqol.v3i12.151 


\subsection{Introduction}

Government environmental programs require public awareness, and active engagement as these are crucial success factors of most sustainable waste management programs (SWM) (Kamaruddin et al. 2013; Kamaruddin \& Omar 2011). Thus, there is a need to evaluate public opinion and practice regarding such programs. Waste composition data from Majlis Perbandaran Subang Jaya (MPSJ) (2014) shows that organic waste (37\%) is second largest after recyclable material (46\%), but most organic waste such as green or food waste are not recycled. MPSJ through its initiative with the Japanese Government undertook the Basic Promotion Plan for Biomass Utilization with the aim to promote the Biomass Town Concept in 2012. This exploratory study intends to highlight the level of awareness and practice of residents of the case study area regarding bio mass initiatives and proposes practical steps to encourage residents towards sustainable waste management. The researchers of this study interviewed five key stakeholders and obtained self-reported responses using questionnaires from 120 residents of Subang Jaya. Through descriptive analysis, the findings of this case study indicate that having awareness and knowledge regarding biomass waste management does not necessarily result in actual sustainable waste practice. This paradox in knowledge and environmental practice is consistent with other similar studies (Kamaruddin et.al. 2016; Voyer et al. 2015). Some interventions are required, e.g., material and monetary incentives/rewards; more publicity and practical programs that focus on different age groups; involvement of CSR that can be implemented to support SWM.

\subsection{Literature Review}

The Malaysian National Solid Waste Management Plan and the Rio Declaration of 1992 identify that environmental and sustainable waste management require the active involvement of both authorities and communities. The long-term growth strategic planning serves as a guide and the basis for solid waste policy and practice in Peninsular Malaysia until the year 2020.It acts as a foundation for sustainable future development in Malaysia. Inter-government cooperation within federal, state and local government is crucial for this effort to succeed. Public participation is imperative, and a social framework needs to be adopted which comprise making the public aware, understand, partner with others and take actions towards sustainable waste management (Embong et al. 2013; Kamaruddin et al. 2013).To follow the waste hierarchy option, any transformation in current solid waste management practices must have clear objectives and targets. The actions taken must care about strategic aspect (environmental, political, economic, institutional, social, technical and also financial) and the functional elements (collection, transfer, recycling, treatment, and disposal). Local authorities are encouraged to introduce new initiatives and economic approaches such as incentives and collection fees to reduce the number of household wastes. 


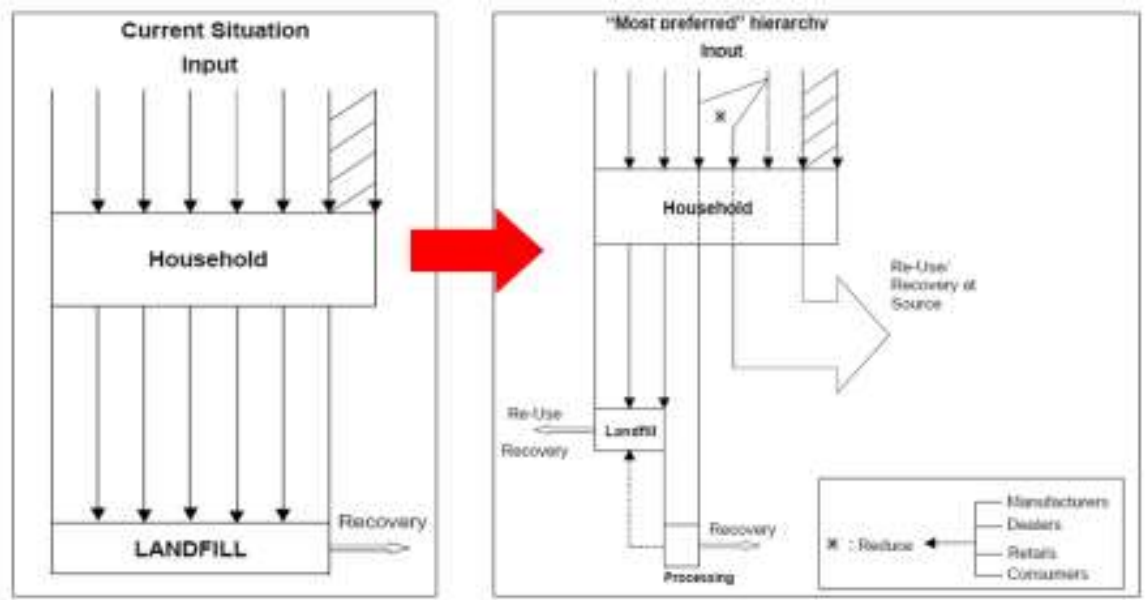

Fig. 1: Implementation of Waste Hierarchy in Waste Stream Flow (Source: Department of Local Government MHLG, 2005).

According to Sarkanen \& Tillman (2013), biomass is the process of conversion of nonrecyclable waste materials (or organic materials) into benefit able heat, electricity and fuel using several of the method, including anaerobic digestion, combustion, pyrolization, gasification and landfill gas (LFG) recovery. Currently, in Malaysia, waste-to-energy or biomass initiatives are implemented by using agricultural residues as a feedstock. In Malaysia, only $9.5 \%$ is sourced from municipal waste and the residual waste from other agricultural industries. MPSJ's decision to launch the bio Mass town concept with the Serdang Biomass Town Project together with MPSJ Bandar Bukit Puchong Integrated Biomass Centre in 2012, showed its commitment to a local government authority (LA) to use biomass initiatives as a strategy to minimize waste generation. Data from the LA's waste composition study in Subang Jaya showed that waste in that municipal consist of $46 \%$ recyclable material, $37 \%$ organic waste and $17 \%$ others waste (MPSJ, 2005). From its total waste recovery rate of $20.16 \%, 19.94 \%$ is from the recovery of recyclable material and $0.22 \%$ from the utilization of organic waste using biomass initiative. Key challenges in recovering municipal solid waste as biomass source are to increase household waste separation activity and high expenditure of maintenance. The waste management budget of the local authority usually takes about a quarter of the total revenue thus reduces the budget for other development.

\subsection{Methodology}

Subang Jaya City covers $161.1 \mathrm{~km}$ square that includes four main zones: Subang Jaya Town, Kinrara Town, Puchong Town and Seri Kembangan Town. There are three MPSJ's biomass facilities i.e. Integrated Biomass Centre Bandar Bukit Puchong, Serdang Wet Market 
Anaerobic Digestion Biogas Plant and Serdang Wet Market Vermicomposting Centre.

In 2013, MPSJ was awarded as a 5-star local authority under the Malaysian Local Authority Star Rating System, organized by Ministry of Housing, Local Government \& Urban Well-Being. This city has a high population of 642, 100 in 2015.There is a total of 92,036 housing units in MPSJ area which comprise of terrace houses, flats, squatter houses, semidetached houses and bungalows as shown in Table 1.In this study, questionnaires distributed at random to different households in Subang Jaya Town, Kinrara Town, Puchong Town and Seri Kembangan Town. The researcher obtained 120 completed survey forms. From the 120 respondents, 44 respondents or $36 \%$ aged between $40-49$ years followed by 40 respondents aged between 30-39 years (33\%). 20 respondents were aged $20-29$ years $(20 \%)$, and finally, eight respondents for each were aged $11-19$ years $(7 \%)$ and aged $50-59$ years $(7 \%)$.

Other primary data obtained through expert interviews with stakeholders revealed officials and waste managers views on the issues and challenges of the biomass initiative. Secondary data from the local authority include the waste composition produced by the household of different income levels and data for used cooking oil for the biodiesel project.

Table 1 : Housing Types in MPSJ Area

\begin{tabular}{cccccc}
\hline Sub-areas & Terrace & Flats & Semi-D & Bungalows & Total \\
& & & & & \\
\hline \hline Seri Kembangan & 12,647 & 5,422 & 488 & 394 & 18,951 \\
\hline Kinrara \& Puchong & 17,814 & 12,552 & 539 & 579 & 31,484 \\
\hdashline Subang Jaya & 22,459 & 13,540 & 1,402 & 1,141 & 35,542 \\
\hline Total & 52,920 & 31,514 & 2,429 & 2,114 & 85,977 \\
\hline
\end{tabular}

\subsection{Results and Discussion}

Under the Biomass Town Project, MPSJ collected food waste from various sources such as housing area and food court and processed into bio-compost. A mechanical process (composting machine) is used to process food waste into bio-fertilizer compost product. The secondary data obtained from MPSJ (Table 2) indicate that organic waste is produced by every household regardless of the household income at an average at $48 \%$ of the waste composition. Yard waste is highest among the high-income households.

Table 2: Waste Compositions Based on Income Level of Household in MPSJ Area.

\begin{tabular}{|c|c|c|c|c|c|}
\hline No & Categories & $\begin{array}{l}\text { High } \\
\text { Income } \\
\text { RM8001 and } \\
\text { above } \\
\text { Unit in \% }\end{array}$ & $\begin{array}{l}\text { Medium } \\
\text { Income } \\
(\text { RM3001-RM8000) }\end{array}$ & $\begin{array}{l}\text { Low } \\
\text { Income } \\
\text { (RM3000 } \\
\text { and below) }\end{array}$ & Average \\
\hline
\end{tabular}

Organic

$\begin{array}{llllll}1 & \text { Food waste } & 40.47 & 48.62 & 55.02 & 48.04 \\ 2 & \text { Bones } & 1.69 & 0.52 & 1.57 & 1.26 \\ 3 & \text { Waste papers } & 16.34 & 20.09 & 14.84 & 17.09 \\ 4 & \text { Plastics }(F) & 4.46 & 5.33 & 6.25 & 5.35\end{array}$


Kamaruddin, S.M., et.al. / Asian Journal of Quality of Life (AjQoL), 3(12) Jul / Aug 2018 (p.147-155)

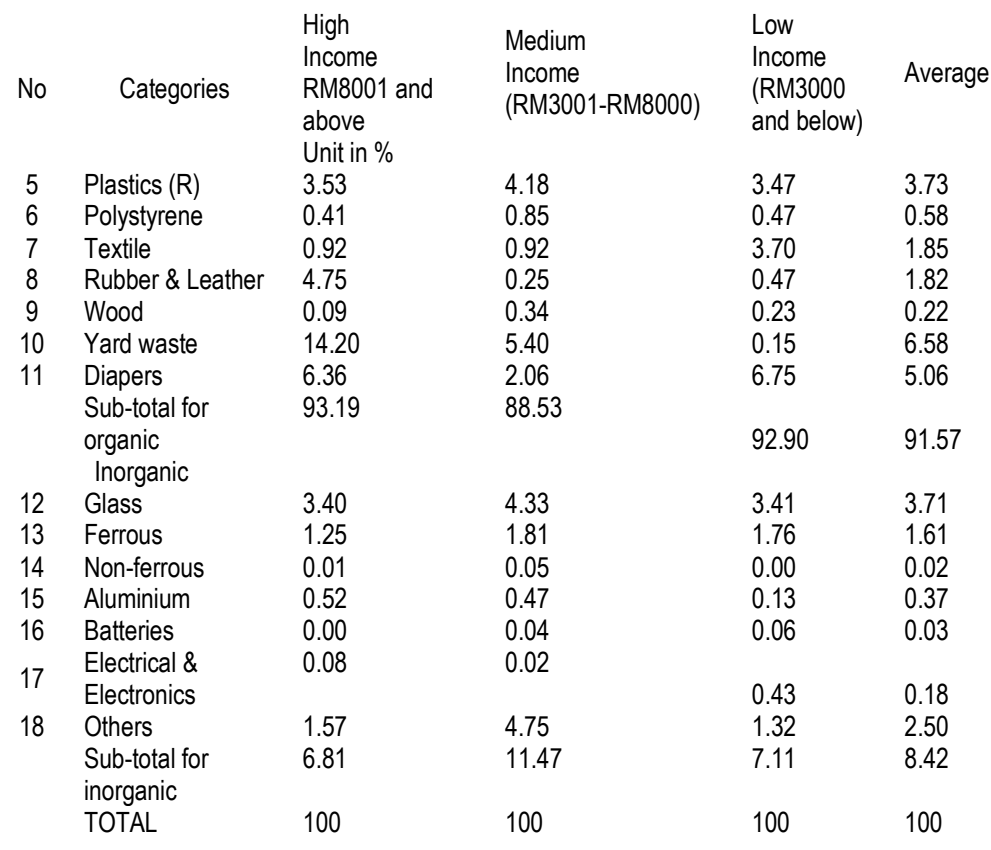

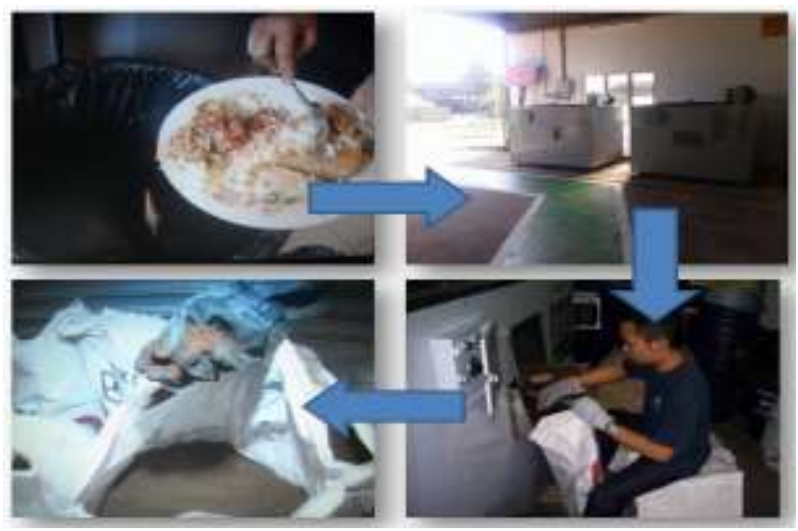

Figure 2: Flow of Food Waste Composting Process

(Source: Department of Environmental Management of MPSJ, 2014).

\subsection{Used Cooking Oil Biodiesel Project}

Used cooking oil biodiesel project is another waste-to-energy conceptual project. This project involves the process of collecting used cooking oil from a restaurant, food court and 
household area before treatment process to transform into biodiesel.This project runs under a smart partnership program, between MPSJ and a private company. MPSJ gives permission and space for this company to locate biodiesel machine at MPSJ Integrated Biomass Centre Bandar at Bukit Puchong. The data indicates residents' support for the program is increasing.

\subsection{Home Composting Project}

Home Composting is a green activity and simple mini project of applying the concept of waste-to-wealth among the public. MPSJ encourage residents to run composting activities individually at their home by supplying free composting bin to separate organic waste and practice home composting. According to Department of Environmental Management of MPSJ (2014), from 2010 until 2014, more than 750 residents practice composting, and this is a good indicator of public engagement in the Biomass Town Project.

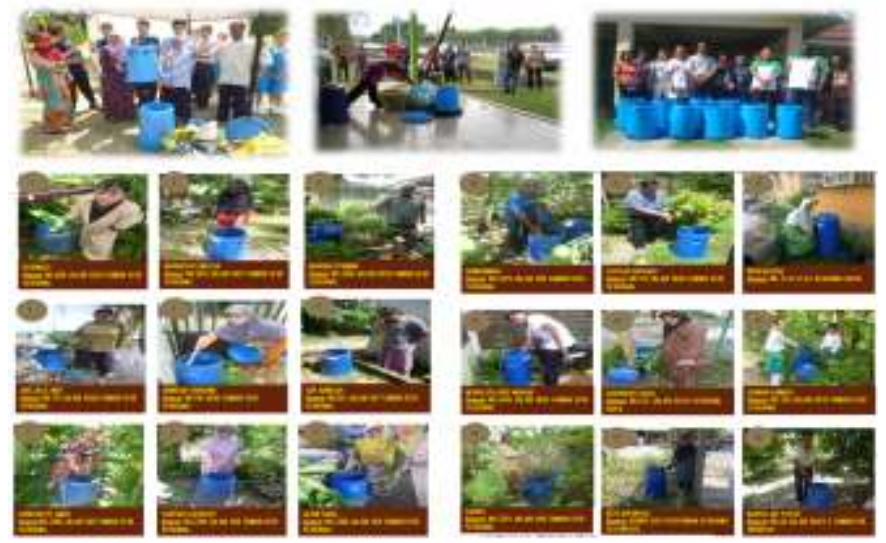

Fig 3: Public Participation for Home Composting Project (Source: Department of Environmental Management of MPSJ, 2014)

\subsection{Communities opinions related to bio mass town program}

The majority of respondents are aware of the Biomass Town Program launched in 2012.(See Table 7 ). $59.2 \%$ or 71 of them had heard and knew about this Subang Jaya Biomass Town initiative conducted by MPSJ. However, $40.8 \%$ which is 49 respondents were unaware about this initiative.

The respondents that were unaware attributed to the 'lack of the publicity given' (57.1\%) followed up by 'always being away' at $22.44 \%$ and 'new resident' at $20.41 \%$. However, all respondents have gained information about the biomass project from various sources (See Figure 7). Advertisements, neighbors, and officemates also relay the information. Television is the medium that gave the least information to respondents. Respondent's suggest that distributing more pamphlet and brochure about the Subang Jaya Biomass Town Program (63.3\%) could help to raise more awareness while $36.7 \%$ answered that getting regular feedback about the program is useful. 


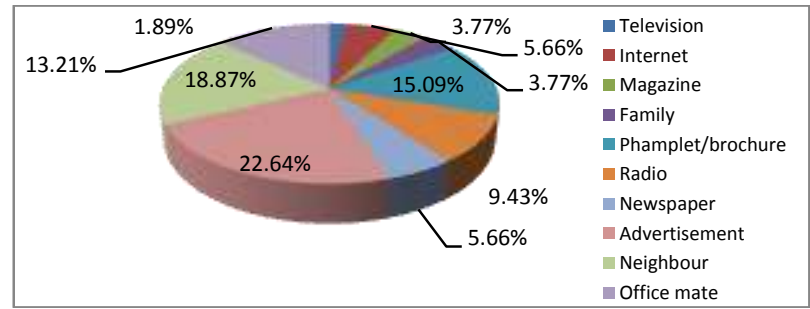

Figure 4: Sources of Subang Jaya Biomass City Information.

\subsection{Communities Knowledge of the Bio Mass Program}

Table 3 shows the respondents' household practices. They were given a choice to answer the questions using scale mark given of (1) Strongly Disagree,(2) Disagree, (3)Agree and (4) Strongly Agree.

Table 3:Scale of Practice.

\begin{tabular}{|c|c|c|c|c|c|}
\hline \multirow[t]{2}{*}{ No. } & & \multicolumn{4}{|c|}{ (Disagree) Scale (Agree) } \\
\hline & & 1 & 2 & 3 & 4 \\
\hline 1. & $\begin{array}{l}\text { After eating, I separate food waste from other waste } \\
\text { (plastic, paper, straw) before threw into the garbage. }\end{array}$ & 18 & 69 & 20 & 13 \\
\hline 2. & $\begin{array}{l}\text { I separated the wastes generated from home before } \\
\text { generator collected the waste. }\end{array}$ & 16 & 65 & 25 & 14 \\
\hline 3. & $\begin{array}{l}\text { I did not use recyclable food container because the } \\
\text { price is costly compared to polystyrene. }\end{array}$ & 8 & 43 & 61 & 8 \\
\hline 4. & I have encouraged my family to practiced recycle. & 10 & 43 & 55 & 12 \\
\hline 5. & $\begin{array}{l}\text { I participated in the recycling program in my } \\
\text { residential area. }\end{array}$ & 5 & 59 & 33 & 23 \\
\hline 6. & I recycled solid waste to make money. & 26 & 69 & 19 & 6 \\
\hline 7. & I threw food waste in the garbage. & 12 & 21 & 76 & 11 \\
\hline 8. & I supported composting practice from food waste. & 20 & 15 & 76 & 9 \\
\hline 9. & I reused food waste to make compost. & 15 & 79 & 21 & 5 \\
\hline 10. & Usually I threw used cooking oil into the sink. & 8 & 31 & 72 & 9 \\
\hline 11. & Usually I threw used cooking oil into the drain. & 76 & 28 & 9 & 7 \\
\hline 12. & $\begin{array}{l}\text { I collected used cooking oil into the bottle before I } \\
\text { threw into the garbage. }\end{array}$ & 76 & 12 & 27 & 5 \\
\hline 13. & $\begin{array}{l}\text { I collected used cooking oil into the bottle before } \\
\text { recycling. }\end{array}$ & 64 & 21 & 26 & 9 \\
\hline
\end{tabular}

From the information in Table 9, only $27 \%$ of the respondents separate their food waste. For recycling practice, most of the respondents (69 respondents) did not participate in the recycling program even there is recycling center in Subang Jaya City. Other studies (Xu et al. 2016) highlight that people feel recycling can be an inconvenience when the recycling center is far from their house (Kamaruddin 2010). However, 67 respondents (59\%) encouraged their family member to recycle but may not practice recycling. Most of the respondents (69) used recyclable food container compared to polystyrene. This practice is commendable. Most of them used the plastic bag given instead of bringing along the recyclable bag to the shop. This practice may contribute to more generation of plastic waste 
(Asmuni et al. 2015). Many of the respondents (72\%) also throw away the residue of food waste (87 respondents) into the garbage instead of reusing it for composting. This practice suggests the lack of knowledge about the composting process and program. From the table, few respondents gain financial incentive. Related to the respondent's practice in the handling of used cooking oil, most of them (81 respondents or $67 \%$ ) throw away the used cooking oil into the sink despite having the knowledge that it is processable as biodiesel. This paradox suggests that having knowledge may not transform into practice despite MPSJ's effort to engage a company to collect used cooking oil within the Subang Jaya neighbourhood.

\subsection{Respondents' Opinion on the success of the Bio Mass Program}

The survey revealed that $74 \%$ thought that the Biomass Town Program is not successful. Those that were positive about its success believed that the program had encouraged residents to practice separation of waste and recycling practices more and the program should continue.

\subsection{Professional stakeholders' opinions related to biomass town program}

The information from the interview found that the professional stakeholders believe that the biomass program is beneficial to the urban community as part of an integrated waste management. They agree that residents should consider waste as a "waste of wealth concept", collective cooperation and participation among residents are integral, processing and operational cost could be reduced and raising awareness to require programs that provide incentives to residents with local authorities direct contact as 'seeing is believing". The expert stakeholders emphasise that financial backup and continuous feedback from the government is necessary to ensure success of the programme.

\subsection{Conclusion}

Several issues require due consideration. The first is about the need to increase awareness using the most practical and preferred medium and method, i.e., encouraging neighbours and colleagues towards more active participation in biomass activities. MPSJ could also periodically monitor and give monetary incentives to the participants of the biomass program and acknowledge neighbourhood communities success. Another issue is the selection of the area for biomass facilities setup where the location must be in the right place, convenient to the public. In addition to ensuring planning standards and buffering is in place (Musthafa et al. 2015) facilities need to be set up in an area that has high waste generation. The third issue is the sustainability of organic waste supply is highly linked to a successful source separation program, and the residents may be unaware or need to be trained with proper knowledge of this. Most of the respondents agree that this biomass initiative only gives a little impact but has enormous potential in the future. Where it only reduces $2 \%$ of waste generation in Subang Jaya City, it is due to stakeholders not collectively cooperating. Although only a small portion of the public is starting to know and practice the biomass activities such as home composting, and waste separation this is understandable since the biomass program was only in launched for the last 3-4 years ago. 


\section{References}

Embong, A. M., Hashim, H. M., Noor, A. M., Yaacob, R. A. I. R., Seng, L. K., \& Malik, N. A. (2013, November). Assessing the understanding and practices of $3 R^{\prime}$ s among the secondary school students. In Environment and Electrical Engineering (EEEIC), 2013 13th International Conference on (pp. 6-11). IEEE

Kamaruddin, S. M., Ahmad, P., \& Alwee, N. (2016). Community Awareness on Environmental Management through Local Agenda 21 (LA21). Procedia-Social and Behavioral Sciences, 222, 729-737.

Kamaruddin, S. M., Pawson, E., \& Kingham, S. (2013). Facilitating Social Learning in Sustainable Waste Management: Case study of NGOs Involvement in Selangor, Malaysia. Procedia-Social and Behavioral Sciences, 105, 325-332.

Kamaruddin, S.M.,Omar D.B. (2011) Waste management and the role of waste administrators in Selangor, Malaysia. 3rd International Conference on Management of Natural Resources, Sustainable Development and Ecological Hazards - Ravage of the Planet III, RAV 2011 - Selangor, Malaysia

Kamaruddin, S.M. (2010) Factors that influence urban secondary students' recycling participation in Selangor, Malaysia. International Journal of Learning Volume 17, Issue 6, 2010, Pages 215-230

Majlis PerbandaranSubang Jaya. (2014). Booklet - Pusat Biomass Bersepadu MPSJ Bandar Bukit Puchong. Government printer.

Musthafa, S. N. A. M., Leh, O. L. H., Omar, D., \& Karuppannan, S. (2015). Theoretical Review on Environmental Health in Relation to Neighbourhood Planning and Human Physical Activity. Procedia-Social and Behavioral Sciences, 201, 325-332.

Sarkanen, K. V., \& Tillman, D. A. (Eds.). (2013). Progress in biomass conversion (Vol. 1). Elsevier.

Xu, D. Y., Lin, Z. Y., Gordon, M. P. R., Robinson, N. K. L., \& Harder, M. K. (2016). Perceived key elements of a successful residential food waste sorting program in urban apartments: Stakeholder views. Journal of Cleaner Production. 